\title{
El primer Centenario de la Restauración y las celebraciones en Córdoba (Argentina). La fachada de la iglesia jesuítica.
}

\author{
Carlos A. Page*
}

\section{Recibido: 10 de mayo de 2014}

\section{Evaluado: 28 de junio de 2014}

El 7 de agosto de 1914 se cumplía el primer centenario de la reincorporación de los jesuitas al mundo católico. Con esta conmemoración la comunidad cordobesa pensó que una buena forma de adherir a la celebración, sería concluyendo la fachada de la iglesia jesuítica del confiscado edificio del Colegio Máximo creado por el P. Diego de Torres, o también llamada Universidad de San Ignacio, como se comenzó a denominar desde que tuvo sus propias Constituciones en 1664, redactadas por el P. Andrés de Rada.

El diario católico de la ciudad de Córdoba: “Los Principios”, dirigido por el abogado Lisardo Novillo Saravia (1882-1962), fue un medio periodístico que llevó al detalle aquella iniciativa. Anunció que el 2 de abril de 1913 se había realizado una “asamblea popular”, convocada por el superior de la residencia, el jesuita valenciano P. Salvador Barber ${ }^{1}$ por inquietud de la Congregación de las Hijas de María. El sacerdote expresó en la oportunidad la necesidad y ocasión para que se concluya la iglesia: "dándole lo que le falta, haciendo lo que, por ignoradas causas, se dejó de hacer: la fachada”. Faltaban 16 meses para festejar la Restauración que por la bula Sollicitudo omnium

\footnotetext{
* Arquitecto y Doctor en Historia. Investigador del CONICET (CIECS-UNC).

${ }^{1}$ El P. Salvador Barber i Escivá nació el 28 de mayo de 1848 en Alquería de la Condesa, Valencia, ingresando a la provincia jesuítica de Aragón en 1864. Obtuvo su sacerdocio en Banyoles, Girona, de manos del obispo Constantino Bonet en 1873. Dos años después llegó a la Argentina, pasando por el Colegio del Salvador en Buenos Aires. Luego de ello fue enviado a la residencia y noviciado de Córdoba en 1897, y posteriormente al Colegio de la Inmaculada de Santa Fe donde falleció en 1932 (Furlong, 1944: 162).
} 
ecclesiarum del Papa Pío VIII había favorecido el regreso de los jesuitas. Las justificaciones del emprendimiento giraban en torno a que:

"La fachada de la Compañía causa malísima impresión a los turistas que visitan nuestra ciudad, en la cual por su historia, y por el nombre de docta que se granjeó desde hace siglos, no espera al visitante que a ello viene, sino cosas bien acabadas y dignas de su fama" ${ }^{2}$.

Pero se preveía alguna resistencia al proyecto que se convirtió en un interesante debate, quizás de los primeros en Argentina, en cuanto a la consideración del patrimonio arquitectónico entendido como tal. Por un lado estaban los "progresistas" que querían "restaurar" el frente, pero a la vez enriquecerlo con una ornamentación que pensaban debía ser ostentosa. Por el otro, los "conservadores", que sustentaban la idea que la iglesia debía ser respetada en la concepción original. En medio de ello había un total desconocimiento de la historia del edificio, incluso de varias intervenciones recibidas posteriormente a la expulsión $^{3}$. La más evidente era que el chapitel del lado sur había sido dañado por un rayo a principios del siglo XIX y se construyó uno mucho más ornamentado que el original, desconociéndose el suceso. Y todos pensaban que ese, por su "belleza", era el original y había que derribar el prismático de la torre norte, pues debía ser reemplazado por ser menos "estético". Y así se hizo como veremos luego. Otro tema es que se había revocado la fachada, que por entonces marcaba una profunda grieta $^{4}$

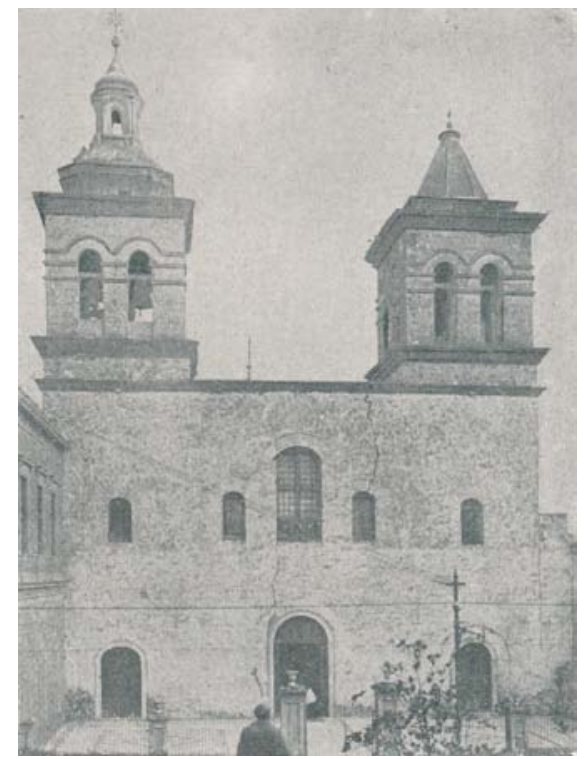

Fig. 1. Esta imagen corresponde al año 1913. Nótese el chapitel del siglo XIX a la izquierda y el original a la derecha. También se puede apreciar la reforma de las aberturas que de arcos carpanel se las transformó en arcos de medio punto y finalmente el revoque con su grieta del lado derecho.

\footnotetext{
${ }^{2}$ Los Principios, 4 de abril de 1913.

${ }^{3}$ La historiografía de la iglesia jesuítica comenzó en esta oportunidad con un limitado folleto de 36 páginas de Mons. Pablo Cabrera (1913). Siguió el P. Pedro Grenón SJ, quien publicó con el seudónimo de Terencio Baggio (1916); un trabajo que con los años y sucesivas investigaciones se probó lo equívoco del mismo. Mejoró luego con otras dos pequeñas obras (1920) y (1938). También trabajó el tema el arquitecto Juan Kronfuss (1921), con muchas inexactitudes. Varias décadas después publicó una serie de artículos Santiago Sosa Gallardo, entre 1949 y 1965, donde puntillosamente agota en forma general el tema. Aunque lo retomamos (Page, 1999), y más específicamente en artículos puntuales (Page, 2011).

${ }^{4}$ Esta grieta era bastante antigua, como lo confirma un inventario que transcribió el P. Cabrera de un libro original depositado en el Colegio Monserrat con el rótulo "Inventarios 1778-1839". No tiene fecha pero consigna que el mismo se hacía por ingresar como rector don Benito Lascano por orden del gobernador Roque Funes que, al igual que el rector gobernaron escasos meses de 1831. Dicho inventario expresa de la iglesia "pared de calicanto, con su pretil enladrillado, dos torres con sus campanas grandes, Relox de
} 
desconociéndose la existencia del proyecto original (Fig. 1). Varios años después una detenida investigación e intervención arquitectónica realizada por el arquitecto Carlos Onetto, devolvió la fachada al estado que al menos tenía para la época de la expulsión. Pero el debate de 1913 valió la pena en cuanto al aprendizaje que dejó sobre la valoración de nuestro patrimonio.

\section{Entre seudos “conservadores” y "progresistas"}

El debate se extendió con calor y entusiasmo fervoroso en las reuniones convocadas al efecto, como en tertulias sociales y en la prensa. Para tener una idea de la magnitud asignada diremos que a la invitación del P. Barber concurrieron el flamante gobernador electo, diputados y senadores, como a su vez lo más alto de la jerarquía eclesiástica, amén de reconocidos ingenieros, abogados, artistas y personalidades influyentes.

El mismo día de la “asamblea”, un artículo de Rafael Moyano López fue destinado a aplacar los posibles embestidas contrarias, exponiendo que cualquier reforma necesita previamente "un estudio concienzudo" y que no hay que precipitarse en las decisiones que se tomen frente a la necesaria "compostura y renovación de la desnuda y antiestética fachada de la Iglesia, completando, con sujeción a un estilo armónico”5. Pero luego de la “asamblea” se procedió a votar, y a pesar de algunas voces opuestas, se resolvió por mayoría que había que completar la obra con una elegante fachada, designándose una comisión con todos los ingenieros presentes ${ }^{6}$ y un sacerdote jesuita (P. Ortells) para que estudiaran el proyecto de la nueva fachada ${ }^{7}$.

Al otro día la prensa, aparentemente encolumnada con la idea de hacer una nueva fachada, publicó un artículo anónimo, aunque después se supo que era del jesuita Antonio Ortells ${ }^{8}$ quien insistió en el mismo diario el 11 de abril, reafirmando la decisión tomada y hasta arengando a apoyarla con coloquiales y sobrios argumentos discursivos, que terminaron en un elegante folleto, con el título "La fachada de la Compañía. Estudios y

campana que rige al Público; Bóbeda de madera pintada, y dorada sus molduras con una rajadura en la pared del frontis bastante grande dimanada de una Centella...” (Cabrera, 1913: 33).

${ }^{5}$ Los Principios, 2 de abril de 1913.

${ }^{6}$ Eran Luis Achával, Belisario Caraffa, Moisés Granillo Barros, Baltasar Ferrer, Luis Betolli y Juan Morra (Los Principios, 10 de abril de 1913).

${ }^{7}$ Los Principios, 3 de abril de 1913.

${ }^{8}$ El valenciano Antoni Ortells i Cerdá nació el 20 de diciembre de 1861 en Vilareal del Castelo de la Plana, ingresando a la Compañía de Jesús de la provincial de Aragón en 1879 y obteniendo el sacerdocio en Tortosa en 1995. Dos años después estaba en Montevideo y luego en el Colegio del Salvador en Buenos Aires, pasando a Córdoba donde reside entre 1906 y 1914 con algunas interrupciones que lo alejan a Buenos Aires y luego trabaja en Santa Fe y el noviciado hasta 1935 que lo trasladan a Carlos Paz, donde muere el 14 de julio de 1951 (Storni (s/f).

112 Carlos A. Page. El primer Centenario de la Restauración y las celebraciones en Córdoba...: 110-120 
opiniones”, publicado por "Los Principios” en 1913, “a solicitud de la Comisión de Damas auspiciadoras de las obras proyectadas en el histórico frontis", donde se repetía lo publicado en el diario ${ }^{9}$.

Pero también ese mismo día se publicó una carta dirigida al P. Barber firmada por el reconocido artista Emilio Caraffa ${ }^{10}$, quien no había podido asistir a la reunión. Expresa que su opinión se basaba desde su conocimiento de viajes por Europa y Oriente, además de la lectura de casos análogos. Escribe en primer lugar que de conservarse un plano, debe seguirse como fue proyectado y si no se conserva el proyecto no debe hacerse ninguno nuevo: "Más vale el sabor de época y la atmósfera de varias generaciones que rodea la pared de piedra, que todos los proyectos de buenos arquitectos". Es decir que hacía hincapié en que darle una nueva fachada le quitaría "el mérito auténtico de época", es decir su autenticidad.

La noticia de las discusiones de Córdoba llegaron a Buenos Aires y el diario "La Nación" también opinó sobre el tema, inclinándose hacia las consideraciones de Caraffa, no sin congratularse con la actitud del superior de la Compañía de Jesús en convocar a una asamblea pública por el carácter que tiene la iglesia como monumento que no es solo de los jesuitas sino de todo el país. Pero vuelve y acentúa su posición en contra de levantar una nueva fachada, exhortando a reaccionar a tiempo "contra el error determinado por el tic novelero de lo flamante" 11 .

Apenas habían pasado poco más de diez días, cuando un nuevo personaje se sumará al debate y será fundamental en la definición del tema. Era el artista Guido Buffo $^{12}$ (Fig. 2) quien había estado presente en

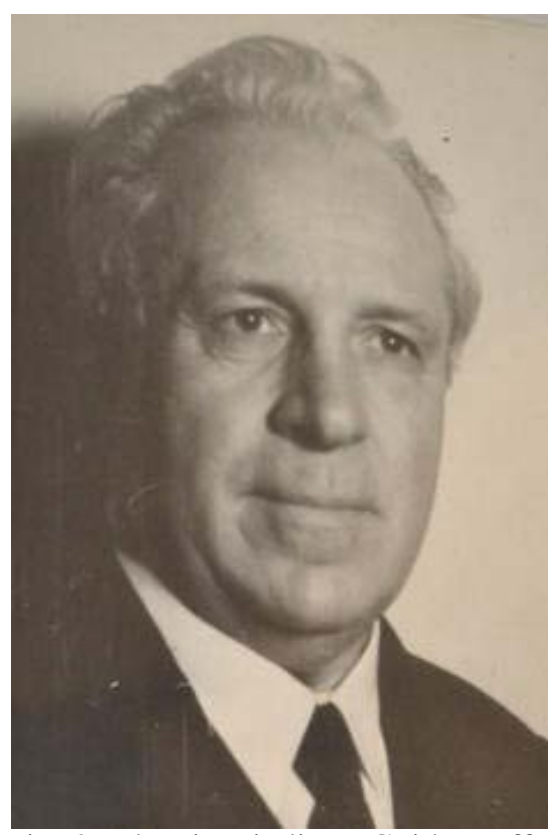

Fig. 2. El artista italiano Guido Buffo (1885-1960).

\footnotetext{
${ }^{9}$ El folleto tiene una introducción editorial del 7 de agosto de 1913, seguido de un "Estudio de la fachada..." del P. Ortells que había publicado el mismo diario el 22 de abril de ese año. Luego sigue un largo artículo de Monseñor Pablo Cabrera que también se había publicado aparte, referida a la historia de la Compañía de Jesús en Córdoba, el primer intento en este aspecto, como señalamos al principio.

${ }^{10}$ El pintor Emilio Caraffa nació en Catamarca en 1863. Estudió en Rosario y Buenos Aires, pasando luego por Italia y España. Regresa y se instala en Córdoba, abriendo una escuela de pintura que aún continúa. Se destacó como retratista y acuarelista, pero una de sus obras más famosas es la pinturas del interior de la Catedral realizadas entre 1908-1914, junto con su equipo compuesto por los artistas José Ferri, Manuel Cardeñosa, Carlos Camilloni, Augusto Orlandi, entre otros. Falleció en Córdoba en 1939 (Gutiérrez y Page, 1999: 91-92).

11 “Lo viejo y lo nuevo”, La Nación, 9 de abril de 1913.

${ }^{12}$ Guido Buffo nació en Trevisto, Italia, el 12 de marzo de 1885. Después de estudiar en París, Turín y Venecia, se radicó en Córdoba en 1910. Allí se casó con Leonor Allende en 1914 con quien tuvo una hija.
} 
la asamblea y publicó un artículo ${ }^{13}$ exponiendo algunas consideraciones poco sustanciosas sobre historia del arte y algunas cuestionables referencias sobre la historia de la universidad, los protagonistas de la "conquista de América" y finalmente envuelve el relato hacia las iglesias de las estancias de Santa Catalina y Alta Gracia. Expone finalmente que la fachada de la primera debía haber inspirado al artista que hizo la iglesia del Colegio, pues el chapitel sur era similar a la iglesia de aquella estancia. Por tanto propuso demoler el chapitel de la torre norte (el original) reemplazándolo por uno similar al de la torre sur y limpiar el revoque de la fachada. Pero Buffo recién empezaba, e iría más lejos.

Por su parte la comisión de ingenieros se reunió el día 9 y resolvió encomendar "al arquitecto Juan Kronfuss (Fig. 3) el estudio de un anteproyecto de fachada, de acuerdo a la arquitectura de la época, conservando las líneas fundamentales del edificio actual”. El austro-húngaro Kronfuss era un estudioso de la arquitectura colonial, y por entonces aún residía en Buenos Aires, anunciando que se trasladaría a Córdoba para delinear su anteproyecto a la vista del mismo templo.

Incluso Kronfuss a los pocos años manifestó en su conocido libro en la parte que hace una muy poco acertada historia de la iglesia, que en la fachada no se nota "la menor disposición que provea la colocación de adornos para futuros tiempos”" ${ }^{\prime 4}$. También el propio arquitecto Buschiazzo afirmó en 1942 que era de la misma opinión ${ }^{15}$.

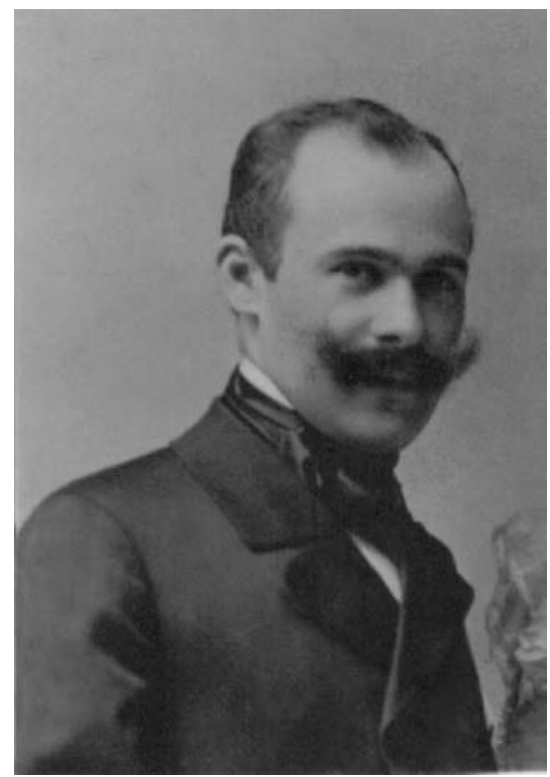

Fig. 3. El arquitecto austro-húngaro Juan Kronfuss en tiempos que llegó a la Argentina.

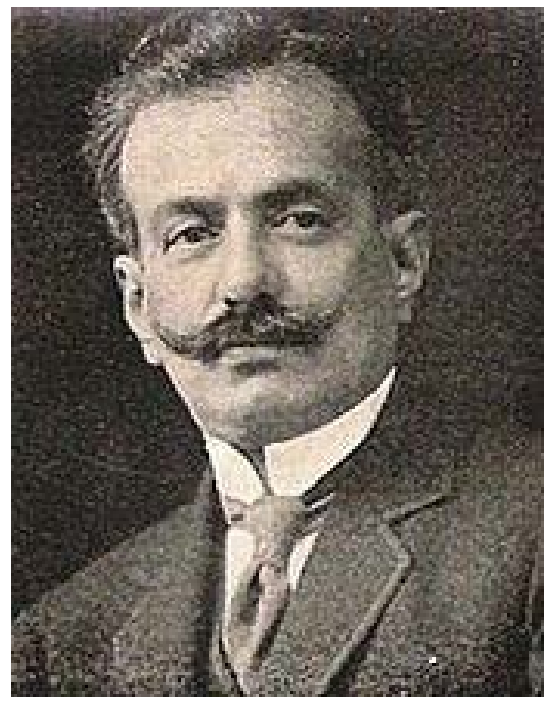

Fig. 4. el gobernador Ramón J. Cárcano durante su primer mandato.

Ambas sufrieron de tuberculosis y murieron en 1931 y 1941, respectivamente. Luego Buffo les levantó una capilla-monumento en homenaje, en las afueras de la ciudad de Unquillo con pinturas murales que no concluye, al fallecer en 1960 (Petriella y Sosa Miatello (s/f).

13 Buffo, 1913.

${ }^{14}$ Kronfuss, 1921: 83.

${ }^{15}$ Buschiazzo, 1942. 
Quien gravitaría fundamentalmente en las decisiones sería el flamante gobernador Ramón J. Cárcano ${ }^{16}$ (Fig. 4). Había ganado las elecciones y le quedaban escasos días para asumir. Era abogado e historiador, contando por entonces con 53 años, pero destaquemos dos aspectos poco conocidos. Él fue quien en 1917 y junto con su ministro Juan B. González presentó, en las Cámaras Legislativas, un pionero proyecto de ley sobre la “conservación de monumentos de carácter histórico y artístico” que no prosperó. El otro tema referido a Cárcano es que en 1938, al crearse la Comisión Nacional de Monumentos presidida por el Dr. Ricardo Levene con ocho vocales, uno de ellos fue justamente Cárcano ${ }^{17}$. Pues estas acciones no se desvinculan de una opinión formada y serena sobre los acontecimientos que se vivían y el gobernador escribió:

"La obra de arte es el patrimonio de un hombre o de una época. Si queda inconclusa, no puede terminarla otro hombre en otra época. Falta la misma idea, la misma inspiración, el mismo ambiente externo, el mismo momento interior (...) No hay otro medio (...) que copiar o interpretar las obras de la época. Realizar en esta forma aquella ocurrencia, es simplemente sustituir el original por la imitación, lo anecdótico por lo falso; destruir lo que ya no se puede restablecer, y colocar en el sitio tradicional la copia banalizada retenida por el viejo marco" ${ }^{18}$.

Lentamente se sumaban voces como la de Ignacio Garzón quien manifestó:

"Entiendo que la verdadera belleza está en lo que mueve el espíritu hacia la contemplación de las obras buenas de los hombres que fueron, como los monumentos levantados a la Divinidad. La estética habla de los sentidos más que al espíritu. El hombre inteligente e instruido siente inefable placer recordando ante la materialidad de los objetos al trabajo y el esfuerzo de sus antepasados. Sería una impiedad o una ingratitud destruir o desfigurar lo ellos levantaron" ${ }^{\prime 19}$.

Pero prevalecía el pensamiento y retórica convincente que bien transmitía el P. Ortells, cuando escribía:

"Pretender conservar como antigüedad el desnudo paredón-fachada sería lo mismo que pedir, en un museo de bellas artes, un lugar de preferencia para un lienzo que no ha visto el pincel, o para un bloque al que no ha tocado el buril, nada más que

\footnotetext{
${ }^{16}$ Ramón J. Cárcano nació en Córdoba en 1860 y falleció en Buenos Aires en 1946. Fue historiador, político conservador y abogado de profesión, doctorándose con la famosa y polémica tesis "De los hijos adulterinos, incestuosos y sacrílegos”, que produjo una dura crítica de la Iglesia. Ocupó numerosos cargos públicos nacionales y provinciales, entre ellos la gobernación de Córdoba por dos periodos (1913-1917 y 1925-1928) (Cárcano, 1965).

${ }^{17}$ Page, 1996: 13-14.

${ }^{18}$ Los Principios, 20 de abril de 1913.

${ }^{19}$ Carta al gobernador Cárcano, Los Principios 19 de abril de 1913.
}

115 Carlos A. Page. El primer Centenario de la Restauración y las celebraciones en Córdoba...: 110-120 
porque el bloque se sacó de la cantera. Yo he dicho -continúa- que ese desnudo muro nada representa de arte, ni de gusto, ni de cultura, ni de historia. Lo que representa arte, y gusto de una época que ya pasó, es el tiempo, pero no su carencia de fachada; ésta, en el estado en que se halla, solamente puede representar o faltar de medios pecuniarios, o carencia de artífices, o negligencia en terminar la obra: ninguna de las tres cosas es digna de memoria" ${ }^{20}$.

\section{El proyecto de Guido Buffo}

Hasta hace pocos años desconocíamos los proyectos de Kronfuss que fueron hallados por casualidad. Ni siquiera hubo posterior referencia periodística a esos dibujos.

Mientras tanto la comisión de ingenieros se reunió el 25 de junio para examinar el anteproyecto del artista Guido Buffo (Fig. 5), quien había sido asesorado por el ingeniero Romagosa, causando la suficiente buena impresión para que la comisión se expidiera definitivamente sobre el asunto.

Este anteproyecto fue acompañado por una nota descriptiva del mismo, intentando justificar la intervención, considerando como premisa que: "la arquitectura colonial se manifestó en América bajo dos instancias históricas. La primera correspondiente a un "carácter severo y maciso (...) arte sobrio y armónico con expresión de calma y solidez”. En tanto que en el segundo periodo "es de un carácter majestuoso pero casi afeminado, más elegante, mucho menos pesado". De esta manera -continúa el polémico discursoprocura armonizar la severidad vetusta del primer periodo, con la esbeltez del segundo. Así que, que en la planta baja donde se sostiene todo el peso de la fachada, arremete con un estilo sobrio para dar el carácter de solidez requerido. Mientras que en la planta siguiente trata el muro sin aquella pesadez para no oprimir la planta baja, pero sin llegar a una situación de esbeltez que no iría de acuerdo a la base.

El portal central y las columnas que sustituyen la base y limitan el cuerpo de las torres, estarían

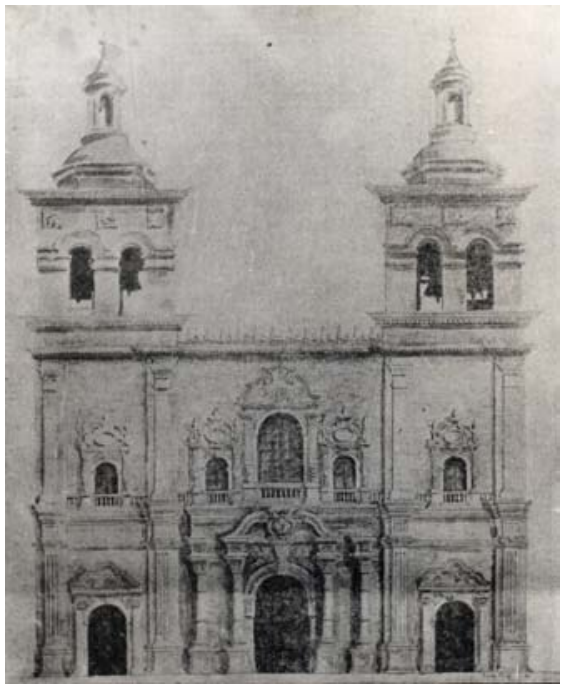

Fig. 5. El proyecto de fachada que realiza el artista Guido Buffo y publica Los Principios del 27 de junio de 1913. inspiradas en la iglesia de San Ignacio Miní, de donde

\footnotetext{
${ }^{20}$ Ortells, 1913.
} 
también se toma la idea de la balaustrada que corre en consonancia con las ventanas y que iría empotrada en la pared.

La ornamentación de las ventanas chicas tendría la influencia del interior de la misma iglesia y la de la estancia de Santa Catalina, donde se manifiesta su pensamiento de serenidad y alivio. Esto iría acompañado de un coronamiento final de todo el conjunto arquitectónico que, como expresa su autor: "sería como una luminosa expresión del espíritu sobre el fuerte pensamiento del hombre que ha contribuido al esplendor de la Religión”.

En cuanto a los materiales a emplearse se requeriría primeramente de una limpieza de todo el revoque con que había sido recubierta, quedando el muro de piedra a la vista. En contraste con esto, los ornamentos serían realizados en piedra sapo, ya que con éste se creaba, no sólo la armonía con el resto del edificio sino que no parecería algo nuevo o ajeno $^{21}$. Lo cierto es que se comenzó por recaudar fondos. Lo primero que se hizo fue demoler el chapitel del norte y sustituirlo por otro igual al del sur que había sido construido, según manifestaba "la tradición oral", luego que un rayo lo destruyera (Fig. 6). Mientras los arcos elípticos de las aberturas fueron reemplazados por arcos de medio punto ${ }^{22}$.

Como señalan Grenón y Sosa Gallardo, cuando se concluyó la restauración del arquitecto Onetto pareció definida una situación en donde el proyecto de Buffo constituyó "un verdadero atentado a la realidad histórica y que la solución pictórica decorativa que sancionó la comisión técnica especial, obra de Guido Buffo, representa una fantasía extravagante, ajena al sentimiento original de la obra” ${ }^{23}$. Finalmente la idea declinó, seguramente ante la ausencia de los cuantiosos fondos requeridos. Ya no había mano de obra indígena barata, y en cuanto a la extracción de materiales, las condiciones habían cambiado notablemente después de más de un siglo. El proyecto quedó como una curiosidad de la historia $^{24}$.

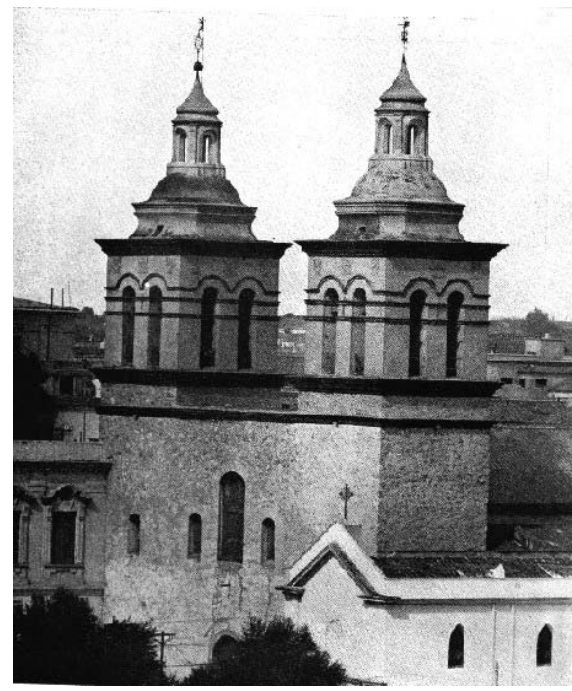

Fig. 6. Las primeras y únicas obras concluidas del proyecto Buffo, fueron los chapiteles de las torres.

\footnotetext{
${ }^{21}$ Page, 1994: 43.

${ }^{22}$ Carta del pintor Guido Buffo dirigida al gobernador el 12 de junio de 1913 y publicada en Los Principios, 27 de junio de 1913.

${ }^{23}$ Grenón y Sosa Gallardo, 1950: 264.

${ }^{24}$ Page, 1999: 159.
} 


\section{Los proyectos de Kronfuss}

Las acuarelas firmadas por Kronfuss fueron halladas en el año 2005 y se encuentran expuestos en el decanato de la Facultad de Derecho de la Universidad Nacional de Córdoba. Son dos proyectos con una variante cada uno, sin diferir de la idea general que tenía Guido Buffo, de imponer el lenguaje neocolonial que estaba en sus inicios, e imponía el Barroco para concentrar la ornamentación en el ingreso y aberturas. La particularidad es que Kronfuss europeíza su trabajo, mientras Buffo compone bajo la premisa de una arquitectura jesuítica local. La fachada en realidad la delinea suavemente, enfatizando los cambios sugeridos. En todos los casos se parte de un cuerpo central que enmarcan dos columnas, los laterales de la puerta de ingreso y ventana del coro, y estas a su vez se suman a otras dos que cierran la ornamentación conteniendo las pequeñas ventanas laterales más próximas a la central. La gran diferencia, entre todos los recursos de estilo es la culminación o remate, donde en dos casos se inscribe el anagrama de Jesús y en otros dos una imagen de bulto, que puede ser por un lado la Virgen y por el otro San Ignacio.
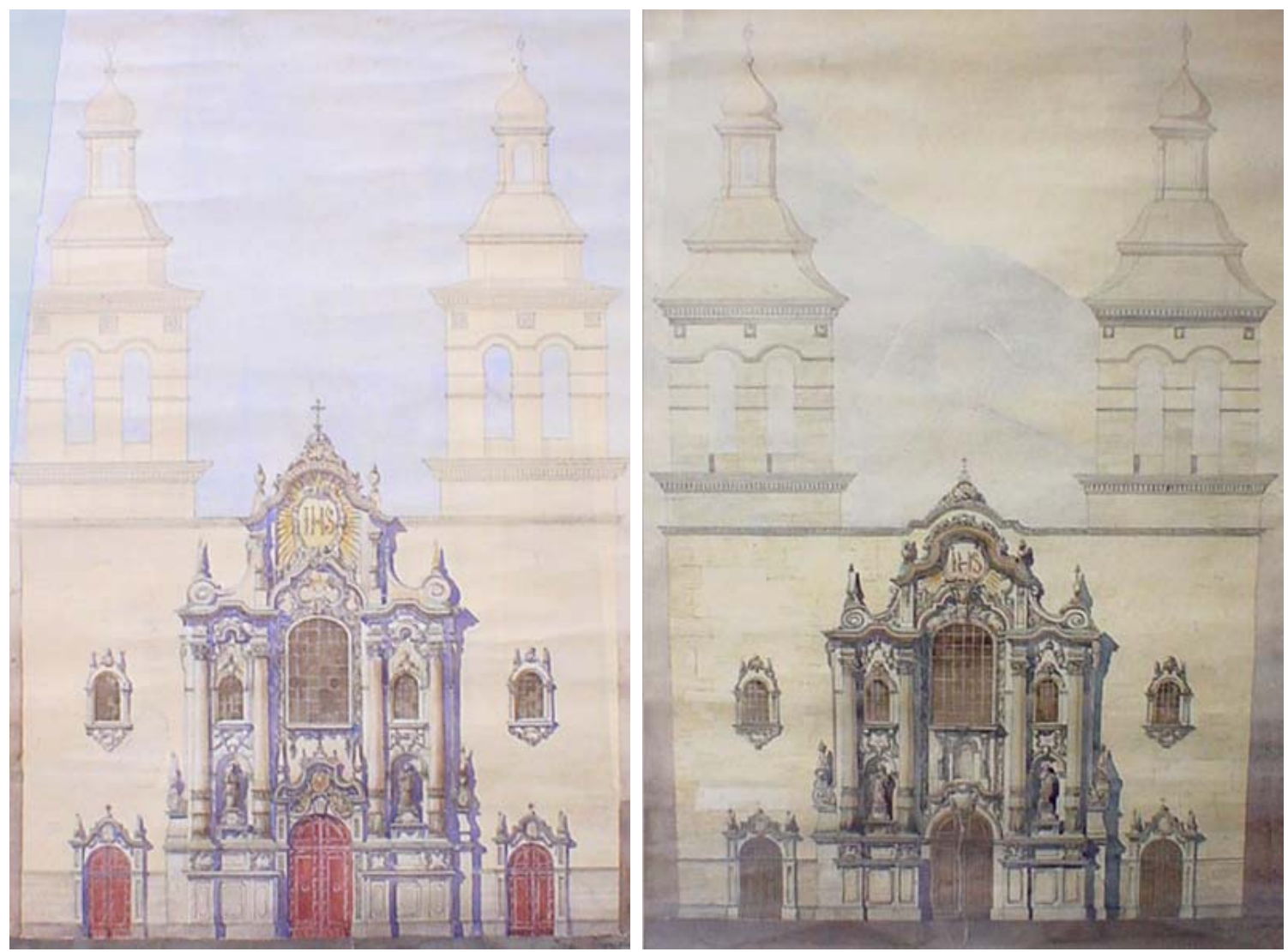

Fig. 7 y 8. Proyecto de Juan Kronfuss con las variantes con el anagrama de Jesús 

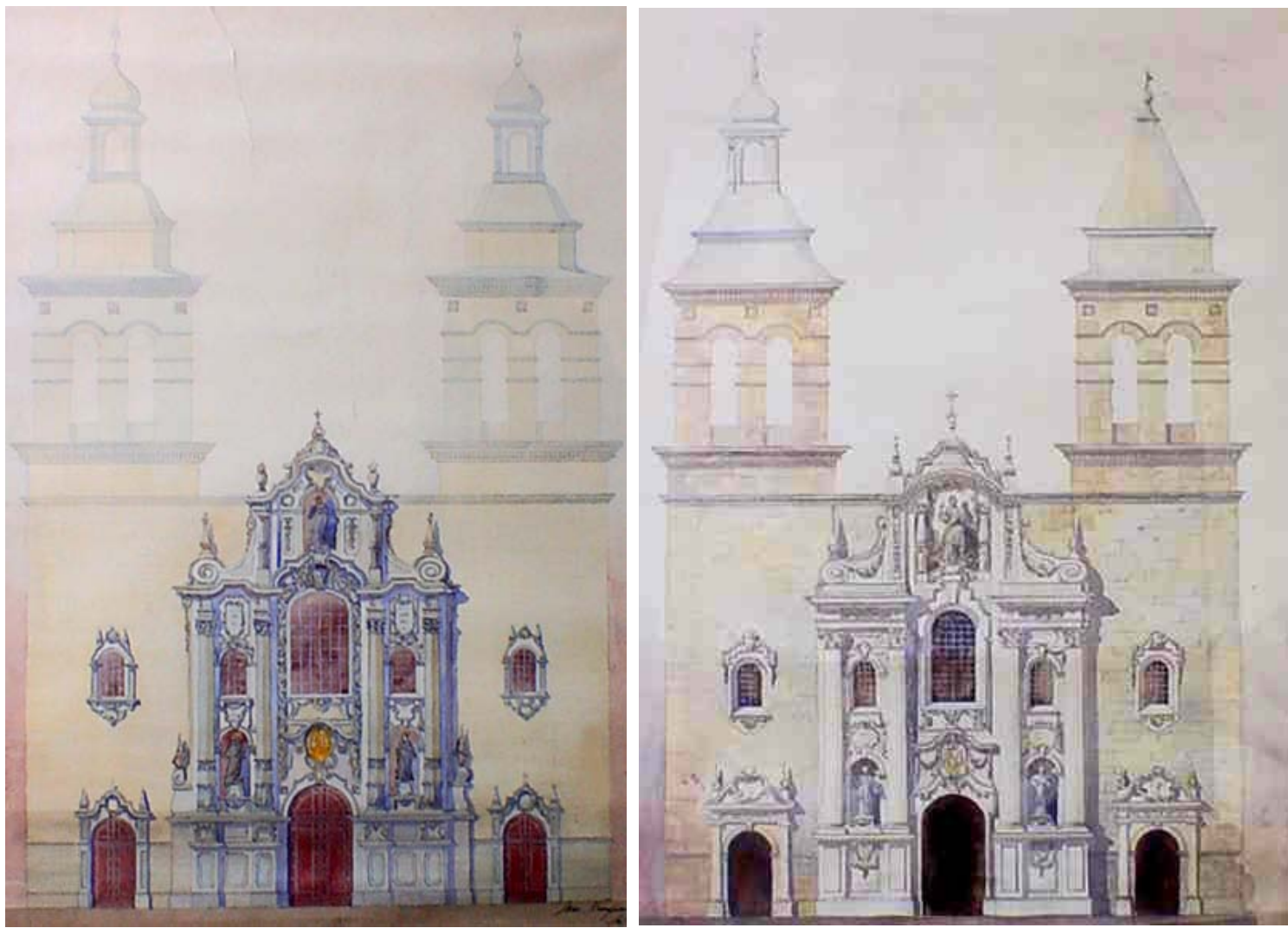

Fig. 9 y 10 Variantes del mismo proyecto rematando con la imagen de San Ignacio.

\section{Bibliografía}

Baggio, Terencio [Pedro Grenón SJ] (1916), La ermita cordobesa de S. Tiburcio y Valeriano, Córdoba: Tip. Vita Coloniale.

Buffo, Guido (1913), "Sobre arte colonial. La fachada de la Compañía”, Los Principios, 10 de abril de 1913.

Buschiazzo, Mario J. (1942), La Iglesia de la Compañía en Córdoba, Buenos Aires: Documentos de Arte Argentino, Academia Argentina de Bellas Artes.

Cabrera, Mons. Pablo (1913), Tesoros del pasado argentino. Dos páginas sobre arte colonial (A propósito de la fachada de la Compañía). Córboba: Los Principios.

Cárcano, Ramón J. (1965), Mis primeros ochenta años. Buenos Aires: Pampa y Cielo.

Furlong SJ. Guillermo (1944), Historia del Colegio del Salvador y sus irradiaciones culturales y espirituales en la ciudad de Buenos Aires, 1617-1943, II Primera Parte 1868-1943, Buenos Aires: Colegio del Salvador.

Grenón SJ, Pedro (1920), “Orígenes de la iglesia de la Compañía de Jesús en Córdoba (R.A.)" separata de la Revista de la Universidad Nacional de Córdoba, Año VII, N ${ }^{\circ}$ 4. 
Grenón SJ, Pedro (1938), “La Compañía de Jesús en Córdoba. Documentación de su establecimiento”, Córdoba: imp. Gutenberg.

Grenón SJ, Pedro y Sosa Gallardo, Santiago (1950), “La fachada de la Iglesia de la Compañía de Jesús en Córdoba”, Revista de la Facultad de Ciencias Exactas, Físicas y Naturales, Universidad Nacional de Córdoba, A. XIII, N 1, enero-marzo.

Gutiérrez, Ramón y Carlos A. Page (1999), La Catedral de Córdoba. Córdoba: Fundación Centro.

Kronfuss, Juan (1921), La arquitectura colonial en la Argentina, Córdoba: Biffignandi

Ortells SJ, Antonio, “Estudio sobre la fachada de la Compañía”, Los Principios, 22 de abril de 1913.

Page, Carlos A. (1990), “La fachada de la Compañía de Jesús (Córdoba)”, DANA, Resistencia, $n^{\circ}$ 28/29.

(1996), Historia de la arquitectura y el urbanismo de Córdoba. Bibliografía General, Córdoba: IICPAyU-FAUyD de la Universidad Nacional de Córdoba.

(1999), La manzana jesuítica de la ciudad de Córdoba, Córdoba: Universidad Nacional de Córdoba-Municipalidad de Córdoba,

------------ (2011), “La cubierta y pinturas de la iglesia de la compañía de Jesús en la ciudad de Córdoba (Argentina)”, Artigrama, núm. 26, pp. 625-648.

Petriella, Dionisio y Sara Sosa Miatello (s/f), Diccionario Biográfico Italo-Argentino, Buenos Aires: Asociación Dante Alighieri. http://dante.edu.ar/web/dic/diccionario.pdf

Sosa Gallardo, Santiago (1949-1965), [siete artículos], Revista de la Universidad Nacional de Córdoba y Revista de la Facultad de Ciencias Exactas, Físicas y Naturales de la UNC.

Storni SJ, Hugo (s/f), “Los jesuitas argentinos (1829-1938)”. Index (digitalizzato da Raúl González Bernardi SJ. http://www.sjweb.info/arsi/documents/Los_jesuitas_argentinos_web.pdf) 